\title{
Evaluación antibacteriana del peróxido de hidrógeno comparado con hipoclorito de sodio sobre cepillos dentales inoculados con Streptococcus mutans
}

Antibacterial Evaluation of Hydrogen Peroxide Compared to Sodium Hypochlorite on Dental Brushes Inoculated with Streptococcus Mutans Avaliação do efeito antibacteriano do peróxido de hidrogênio em comparação ao hipoclorito de sódio em escovas de dente inoculadas com Streptococcus mutans

César Félix Cayo-Rojas ${ }^{1 *}$

Estefany Hilda Rojas-Zubizarreta ${ }^{2}$

Miriam Kelly Nicho-Valladares ${ }^{3}$

Marysela Irene Ladera-Castañeda ${ }^{4}$

Ana Sixtina Aliaga-Mariñas ${ }^{5}$

1 E.P. de Estomatología de la Universidad Privada San Juan Bautista (Perú). Escuela Universitaria de Posgrado, Universidad Nacional Federico Villarreal, (Perú). ORCID: https://orcid.org/0000-00025560-7841

2 Facultad de Odontología y Escuela Universitaria de Posgrado, Universidad Nacional Federico Villarreal (Perú). orCiD: https://orcid.org/0000-0002-1354-343X

3 Facultad de Odontología y Escuela Universitaria de Posgrado, Universidad Nacional Federico Villarreal (Perú). ORCID: https://orcid.org/0000-0001-6019-2559

4 Facultad de Odontología y Escuela Universitaria de Posgrado, Universidad Nacional Federico Villarreal (Perú). E. P. de Estomatología de la Universidad Privada San Juan Bautista (Perú). ORCiD: https://orcid.org/0000-0001-5390-8256

5 Facultad de Odontología y Escuela Universitaria de Posgrado, Universidad Nacional Federico Villarreal (Perú). oRCiD: https://orcid.org/0000-0002-5635-5498 
Recibido: 24 de septiembre de $2019 \cdot$ Aceptado: 9 de septiembre de 2020

Doi: https://doi.org/10.12804/revistas.urosario.edu.co/revsalud/a.10226

Para citar este artículo: Cayo-Rojas CF, Rojas-Zubizarreta EH, Nicho-Valladares MK, Ladera-Castañeda MI, Aliaga-Mariñas AS.

Evaluación antibacteriana del peróxido de hidrógeno comparado con hipoclorito de sodio sobre cepillos dentales inoculados con

Streptococcus mutans. Rev Cienc Salud. 2021;19(1):1-11. https://doi.org/10.12804/revistas.urosario.edu.co/revsalud/a.10226

\section{Resumen}

Objetivo: evaluar el efecto antibacteriano del peróxido de hidrógeno $\left(\mathrm{H}_{2} \mathrm{O}_{2}\right)$ al $6 \%$ comparado con hipoclorito de sodio ( $\mathrm{NaClO}$ ) al $1 \%$ y al $2 \%$, sobre cepillos dentales inoculados con Streptococcus mutans ATcc ${ }^{\circledR}$ $25175^{\mathrm{TM}}$. Materiales y métodos: estudio experimental in vitro, transversal y comparativo. Se utilizaron 60 cepillos dentales, divididos en 4 grupos de 15 cepillos cada uno. El número de muestra lo determinó la fórmula de comparación de medias, después de realizar un estudio piloto, y se seleccionaron por muestreo aleatorio simple. Se aplicaron las pruebas de normalidad de Shapiro-Wilk, y para la prueba de hipótesis, la U de Mann-Whitney. Resultados: $\mathrm{el}_{2} \mathrm{O}_{2}$ al $6 \%$ presentó una media de crecimiento de $2 \times 10^{9} \mathrm{UFc} / \mathrm{mL}$, lo que indica que su efectividad es mayor comparada con el $\mathrm{NaClO}$ al $1 \%$, que presentó una media de crecimiento de $4 \times 10^{9} \mathrm{urc} / \mathrm{mL}$, y esta es menor al $\mathrm{NaClO}$ al $2 \%$, que tuvo $0 \mathrm{uFc} / \mathrm{mL}$ de Streptococcus mutans ( $\mathrm{p}=0,004)$. Conclusión: el $\mathrm{H}_{2} \mathrm{O}_{2}$ al $6 \%$ y el $\mathrm{NaClO}$ al $1 \%$ y al $2 \%$ evidenciaron efectividad antibacteriana, aun cuando fue el $\mathrm{NaClO}$ al $2 \%$ el más efectivo.

Palabras clave: desinfección; peróxido de hidrógeno; hipoclorito de sodio; Streptococcus mutans.

\section{Abstract}

Objective: To assess the antibacterial effect of $6 \%$ hydrogen peroxide $\left(\mathrm{H}_{2} \mathrm{O}_{2}\right)$ compared with $1 \%$ and $2 \%$ sodium hypochlorite, on toothbrushes inoculated with Streptococcus mutans Атсс $^{\circledR} 25175^{\mathrm{TM}}$. Materials and methods: The study design was an experimental in vitro, cross-sectional prospective and comparative study. Sixty toothbrushes were used, which were divided into four groups of 15 brushes. After conducting a pilot study, the sample number was determined by the means comparison formula and these were selected by simple random sampling. These brushes were inoculated with strains of $S$. mutans ATCC $^{\circledR} 25175^{\mathrm{TM}}$. The disinfectants included $\mathrm{H}_{2} \mathrm{O}_{2}$ at $6 \%$ and sodium hypochlorite $(\mathrm{NaOCl})$ at $1 \%$ and $2 \%$. The Shapiro-Wilk test was used to assess normality and the Mann-Whitney $U$ test was applied for the hypothesis test. Results: The $6 \% \mathrm{H}_{2} \mathrm{O}_{2}$ showed an average growth of $2 \times 10^{9} \mathrm{cFu} / \mathrm{mL}$, which indicates that its effectiveness is greater compared to the $1 \% \mathrm{NaClO}$ that showed a growth average of $4 \times 10^{9} \mathrm{cFu} / \mathrm{mL}$ which is less than the $2 \% \mathrm{NaClO}$ that presented $0 \mathrm{cru} / \mathrm{mL}$ of $S$. mutans $(\mathrm{p}=0.004)$. Conclusion: Between $6 \% \mathrm{H}_{2} \mathrm{O}_{2}$ and $1 \%$ and $2 \% \mathrm{NaClO}$, specifically antibacterial detection, $2 \% \mathrm{NaClO}$ was concluded as being the most effective.

Keywords: Disinfection; hydrogen peroxide; sodium hypochlorite; Streptococcus mutans.

\section{Resumo}

Objetivo: avaliar o efeito antibacteriano do peróxido de hidrogênio $6 \%$ em comparação ao hipoclorito de sódio $1 \%$ e $2 \%$, em escovas de dente inoculadas com Streptococcus mutans Aтcс $^{\circledR} 25175^{\text {тм }}$. Materiais e métodos: estudo experimental in vitro, transversal e comparativo. Foram utilizadas 60 escovas de dente, as quais foram divididas em 4 grupos de 15 escovas cada um. O número amostral foi determinado pela fórmula de comparação de médias, após realização de um estudo piloto, sendo selecionado por meio de amostragem aleatória simples. As escovas foram inoculadas com cepas de Streptococcus mutans Aтcc ${ }^{\circledR}$ $25175^{\mathrm{TM}}$. Os desinfetantes utilizados foram peróxido de hidrogênio $\left(\mathrm{H}_{2} \mathrm{O}_{2}\right) 6 \%$ em comparação ao hipoclorito de sódio ( $\mathrm{NaClO}$ ) 1\% e 2\%. Aplicou-se a prova de normalidade de Shapiro-Wilk e como teste de hipótese utilizou-se o U de Mann-Whitney. Resultados: $\mathrm{o}_{2} \mathrm{H}_{2} 6 \%$ apresentou uma média de crescimento de $2 \times 10^{9} \mathrm{UFc} / \mathrm{mL}$, indicando uma efetividade maior em comparação com o $\mathrm{NaClO} 1 \%$ que apresentou uma média de crescimento de $4 \times 10^{9} \mathrm{Ufc} / \mathrm{mL}$, que por sua vez foi menos efetivo que o $\mathrm{NaClO} 2 \%$ que apresen- 
tou uma contagem de $0 \mathrm{ufc} / \mathrm{mL}$ de Streptococcus mutans ( $\mathrm{p}=0,004)$. Conclusão: o $\mathrm{H}_{2} \mathrm{O}_{2} 6 \%$ e o $\mathrm{NaClO} 1 \%$ e $2 \%$, apresentaram efetividade antibacteriana, sendo que o $\mathrm{NaClO} 2 \%$ foi totalmente efetivo.

Palavras-chave: desinfecção; peróxido de hidrogênio; hipoclorito de sódio; Streptococcus mutans.

\section{Introducción}

T as enfermedades orales se controlan minimizando la cantidad de microrganismos, y esto Lse puede lograr mediante una higiene bucal adecuada y el mantenimiento del cepillo dental (1). Hasta la actualidad, el adecuado mantenimiento del cepillo dental ha sido un tema de relativa importancia para la profesión odontológica, ya que existe escasa conciencia pública y poco afán de capacitación por parte del odontólogo; por ello, se considera que un recambio frecuente o una desinfección óptima del cepillo dental evita la focalización y la expansión de una gran cantidad de microrganismos, cuya consecuencia es la aparición o la prolongación de enfermedades bucales (2).

Según los estudios realizados en el 2012 por Gevers et al. y Huse et al., así como los estudios realizados por Nascimento et al., en el 2017, se utilizaron tecnologías de secuenciación de última generación basadas en secuencias de ARNr 16S para definir el microbioma oral y con ello se identificaron más de 700 especies bacterianas que residen dentro de la cavidad bucal (3-6).

Se ha documentado que los cepillos dentales se exponen a contaminación bacteriana después de su uso en la higiene dental y que los microrganismos permanecen en ellos durante varias horas, por lo que es un tema de investigación importante. De ahí que diversos autores hayan planteado estrategias de desinfección; además se ha reportado que la cantidad de contaminación bacteriana en el cepillo dental aumenta con el uso continuo (7-12).

Do Nascimento et al., investigaron 64 cepillos dentales, mediante el método de hibridación Checkerboard ADN e identificaron 32 especies bacterianas en el grupo de control (agua corriente), luego de haber usado el cepillo dental por 7 días, lo cual fue indicativo de contaminación (7).

El peróxido de hidrógeno tiene la capacidad de inhibir el crecimiento bacteriano; entre tanto, el hipoclorito de sodio inhibe la actividad enzimática para las bacterias en crecimiento y daña la membrana y el ADN de estas; además, es hipertónico (2.800 mOsmol $/ \mathrm{kg}$ ) y muy alcalino $(\mathrm{pH}=11.5$ a 11.7). Las propiedades antimicrobianas se deben, además, a la capacidad de oxidar e hidrolizar las proteínas celulares y formar ácido hipocloroso y a la habilidad osmótica de extraer líquidos fuera de las células (2,7,10,13-15).

En vista de la variedad de desinfectantes, se busca obtener el más efectivo y de fácil acceso, frente a los Streptococcus mutans, ya que es el principal agente de la caries dental, 
predominan en las biopelículas de tejidos duros y tienen la habilidad de permanecer en las cerdas de los cepillos de dientes, durante 44 horas (3,9,16-19).

Según lo reportado por Basman et al., en un estudio realizado en 60 personas, sometidas a cepillado dental, tomando como muestra a 10 personas por grupo, se evaluó la eficacia antibacteriana del hipoclorito de sodio al $2 \%$, comparándolo con otras soluciones frente al Streptococcus mutans, y concluyeron que el hipoclorito de sodio al $2 \%$ no eliminaba en su totalidad los Streptococcus mutans presentes en los cepillos dentales (10). Además, Peker et al. evaluaron la efectividad del hipoclorito de sodio al 1\%, en comparación con otras técnicas de desinfección frente al Streptococcus mutans y llegaron a la conclusión de que es un buen desinfectante bacteriano, pero no totalmente efectivo (12). Sin embargo, Han y Dong evaluaron la actividad antibacteriana del hipoclorito de sodio al $6 \%$, en 15 medios de cultivo sembrados con Streptococcus mutans, y para ello utilizaron el método de recuento de colonias y demostraron que el hipoclorito de sodio al $6 \%$ fue totalmente eficaz como antibacteriano después de 30 minutos de aplicación, pero hay que mencionar que no es accesible esta presentación de forma comercial (19).

Por otro lado, Salazar-Chicaiza y Zurita-Solis evaluaron la efectividad del peróxido de hidrógeno al $3 \%$ y al $6 \%$ aplicado a cepillos dentales durante 7 días después de su uso y concluyeron que el peróxido de hidrógeno al $6 \%$ eliminaba totalmente los Streptococcus mutans (2). Por los antecedentes expuestos, se propuso el siguiente objetivo: evaluar el efecto antibacteriano in vitro de la solución de peróxido de hidrógeno al $6 \%$ comparado con la solución de hipoclorito de sodio al $1 \%$ y al $2 \%$ sobre cepillos dentales inoculados con Streptococcus mutans ATCC $^{\circledR} 25175^{\mathrm{TM}}$.

\section{Materiales y métodos}

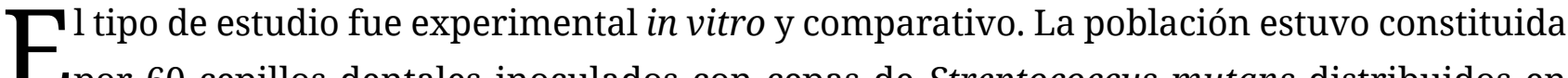
Epor 60 cepillos dentales inoculados con cepas de Streptococcus mutans distribuidos en cuatro grupos de 15 cada uno (peróxido de hidrógeno al $6 \%$, hipoclorito de sodio al $1 \%$ y al $2 \%$ y agua destilada). El tamaño de muestra fue determinado por la fórmula de comparación de medias, después de realizar un estudio piloto y calcular la desviación estándar ( $\mathrm{DE}_{1}=0.3$ y DE $=0.0$ ); además, se seleccionaron por muestreo aleatorio simple con asignación de números para sorteo y así conformar los grupos, con extracción ciega de un número a la vez, sin reposición. Se excluyeron cepillos dentales que contenían agentes antibacteriales.

Dos investigadores de este estudio realizaron el experimento y el registro de datos, calibrados previamente y supervisados en todo momento por un especialista, en el Laboratorio de Microbiología de la Facultad de Odontología de la Universidad Nacional Federico Villarreal (Perú). 
La variable dependiente fueron los Streptococcus mutans ATcC $^{\circledR} 25175^{\mathrm{TM}}$, utilizando como indicador las unidades formadoras de colonias por mililitro (ufc/mL) y las variables independientes fueron la solución de peróxido de hidrógeno al 6 \% y la solución de hipoclorito de sodio al $1 \%$ y al $2 \%$.

Sobre la activación de la cepa de Streptococcus mutans, la bolsa que mantiene la cepa liofilizada (Microbiologics ${ }^{\circledR}$ ) permaneció almacenada a una temperatura de 2 a $8^{\circ} \mathrm{C}$. Luego, la cepa fue activada por medio de un proceso de hidratación. Se presionó (solo una vez) la ampolla en la parte superior del empaque justo debajo del menisco para liberar el hidratante y se presionó el precipitado en el líquido hasta que la suspensión estuvo homogénea. Acto seguido, se saturó el hisopo con los materiales hidratados y se transfirió al caldo de tioglicolato (Merck ${ }^{\mathrm{TM}}$ ). Posteriormente, esta se colocó en la jarra de anaerobiosis (BвLGasPak ${ }^{\circledR}$ ) y se colocó durante $48 \mathrm{~h}$ a $37^{\circ} \mathrm{C}$ en la incubadora Memmert ${ }^{\circledR}$, junto con Anaerocult $\mathrm{C}^{\circledR}(11,12)$.

Se realizó el control de calidad del patrón de turbidez de 0.5 de McFarland BD BвL ${ }^{\circledR}$. Para ello se agitó vigorosamente el patrón en un vórtice Thermolyne ${ }^{\circledR} \mathrm{y}$ se comprobó la densidad de este, determinando la absorbancia mediante un espectrofotómetro DR 6000 Uv-VIs ${ }^{\circledR}$ con un haz luminoso a una distancia de $1 \mathrm{~cm}$. La absorbancia a $625 \mathrm{~nm}$ nos dio un valor entre 0.08 y 0.10 .

Una vez hecha la comprobación, se procedió con la preparación de la suspensión del inóculo de tal manera que se ajustara a $1.5 \times 10^{8} \mathrm{uFc} / \mathrm{mL}$, de acuerdo con la turbidez estándar de 0.5 de McFarland (11). Este ajuste se logró mediante el método de diluciones seriadas 1:10.

Entonces se prepararon las suspensiones para los cepillos ajustándolas a 1/10 $\mathrm{UFc} / \mathrm{mL}$. Los cepillos dentales Oral $\mathrm{B}^{\circledR}$ se esterilizaron en autoclave (Rexall ${ }^{\circledR}$ ) a $121^{\circ} \mathrm{C}$ por $15 \mathrm{~min}$. Posteriormente, se distribuyeron en cuatro grupos A, B, C, D, de 15 cada uno, aplicando el tratamiento de desinfección de la siguiente manera:

Grupo A: peróxido de hidrógeno al $6 \%$.

Grupo B: hipoclorito de sodio al $1 \%$.

Grupo C: hipoclorito de sodio al $2 \%$.

Grupo D: agua destilada (control negativo).

Cada cepillo dental se inoculó con $6 \mathrm{~mL}$ de la suspensión estandarizada con Streptococcus mutans ATc $^{\circledR} 25175^{\mathrm{TM}}$, cubriendo totalmente la cabeza. Luego fueron incubados a $37^{\circ} \mathrm{C}$ durante $24 \mathrm{~h}$ al $5 \%$ de $\mathrm{CO}_{2}$ (12). Posteriormente, los cepillos de cada grupo fueron lavados con suero fisiológico para eliminar el exceso del microrganismo y ser sometidos al tratamiento de desinfección.

Cada grupo de cepillos fue sumergido en $200 \mathrm{~mL}$ de peróxido de hidrógeno al $6 \%$, hipoclorito de sodio al $1 \%$, hipoclorito de sodio al $2 \%$ y agua destilada, durante $10 \mathrm{~min}$ (12).

Después del tratamiento, todos los cepillos se transfirieron a tubos estériles con $15 \mathrm{~mL}$ de suero fisiológico y se vibraron en el vórtice durante un minuto para que los microrganismos presentes en las cerdas del cepillo descendieran a la solución. Después, con una micropipeta 
de $100 \mu \mathrm{l}$ se tomó una muestra de cada solución y se realizaron diluciones seriadas. Luego fueron sembradas en agar base sangre Merck $^{\circledR}$ y se suplementaron con sangre de carnero al $10 \%$ y se agruparon de acuerdo con el tipo de tratamiento sometido. Acto seguido, se trasladaron los cultivos a la jarra de anaerobiosis para incubarlos por $48 \mathrm{~h}$ a $37^{\circ} \mathrm{C}$ con $5 \%$ de $\mathrm{CO}_{2}$ y así poder observar el crecimiento bacteriano (12). Posteriormente, se hizo el conteo en unidades formadoras de colonias por mililitro, de la siguiente manera:

$\mathrm{UFc} / \mathrm{mL}=$ número de colonias $\times$ factor de dilución $/$ mililitros de la muestra

Finalmente, los datos se anotaron en una hoja de cálculo de Microsoft Excel $2016^{\circledR}$ y se exportaron al programa estadístico SPSS ${ }^{\circledR}$, versión 25. Para la decisión de las pruebas estadísticas, se estableció una significancia de $p<0.05$ y grado de confianza al $95 \%$. Se realizó la prueba de normalidad de Shapiro-Wilk, observando que los resultados no presentaban distribución normal; por ello, se utilizó la prueba U de Mann-Whitney para comparaciones independientes (20).

El desarrollo de este trabajo fue aprobado por el Comité de Investigación de la Oficina de Grados y Títulos de la Facultad de Odontología de Universidad Nacional Federico Villarreal.

\section{Resultados}

$\mathrm{L}$

as UFC con el agua destilada (control negativo) fueron $250 \times 10^{9} \mathrm{uFc} / \mathrm{mL}$. Con respecto al peróxido de hidrógeno al $6 \%$, se obtuvieron $12 \times 10^{9} \mathrm{UFc} / \mathrm{mL}$. De la misma manera, respecto al hipoclorito de sodio al $1 \%$, se obtuvo el máximo de $2 \times 10^{9} \mathrm{UFc} / \mathrm{mL}$ y para la concentración del $2 \%$, se obtuvo 0 uFc/mL (tabla 1 ).

Tabla 1. Unidades formadoras de colonias $\left(\times 10^{9} \pm \mathrm{DE}\right)$ de acuerdo con los desinfectantes

\begin{tabular}{lccccc}
\hline \multicolumn{1}{c}{ Grupo } & $\mathbf{n}$ & $\begin{array}{c}\text { Media } \\
\text { (UFc/mL) }\end{array}$ & $\begin{array}{c}\text { DE } \\
\text { (UFc/mL) }\end{array}$ & $\begin{array}{c}\text { Mínimo } \\
\text { (UFc/mL) }\end{array}$ & $\begin{array}{c}\text { Máximo } \\
\text { (UFc/mL) }\end{array}$ \\
\hline Peróxido de hidrógeno al 6\% & 15 & 2.00 & 3.21 & 0.00 & 12.00 \\
Hipoclorito de sodio al 1 \% & 15 & 0.40 & 0.63 & 0.00 & 2.00 \\
Hipoclorito de sodio al 2\% & 15 & 0.00 & 0.00 & 0.00 & 0.00 \\
$\begin{array}{l}\text { Agua destilada } \\
\text { (control negativo) }\end{array}$ & 15 & 250.00 & 0.00 & 250.00 & 250.00 \\
\hline
\end{tabular}

n: muestra; UFC: unidades formadoras de colonias; DE: desviación estándar. 
Tabla 2. Comparación del efecto antibacteriano del peróxido de hidrógeno al $6 \%$ con el hipoclorito de sodio al $1 \%\left(\times 10^{9} \pm \mathrm{DE}\right)$

\begin{tabular}{lcccc}
\hline \multicolumn{1}{c}{ Grupo } & n & $\begin{array}{c}\text { Media } \\
\text { (UFc/mL) }\end{array}$ & $\begin{array}{c}\text { DE } \\
\text { (UFc/mL) }\end{array}$ & Valor de $\boldsymbol{p}^{\boldsymbol{a}}$ \\
\hline Peróxido de hidrógeno al 6\% & 15 & 2.00 & 3.20 & 0.10 \\
Hipoclorito de sodio al 1\% & 15 & 0.40 & 0.63 & \\
Total & 30 & & & \\
\hline
\end{tabular}

a: Basado en la prueba no paramétrica U de Mann-Whitney; n: muestra; UFC: unidades formadoras de colonias; DE: desviación estándar; p>0.05: no es estadísticamente significativo.

De la tabla 2 se observa que no existe diferencia estadísticamente significativa entre el efecto antibacteriano del peróxido de hidrógeno al $6 \%$ y el hipoclorito de sodio al 1\% $(\mathrm{p}=0.10)$.

Tabla 3. Comparación del efecto antibacteriano del peróxido de hidrógeno al $6 \%$ con el hipoclorito de sodio al $2 \%\left(\times 10^{9} \pm \mathrm{DE}\right)$

\begin{tabular}{lcccc}
\hline \multicolumn{1}{c}{ Grupo } & n & $\begin{array}{c}\text { Media } \\
\text { (urc/mL) }\end{array}$ & $\begin{array}{c}\text { DE } \\
\text { (urc/mL) }\end{array}$ & Valor de $\boldsymbol{p}^{\mathbf{a}}$ \\
\hline Peróxido de hidrógeno al 6\% & 15 & 2.00 & 3.21 & \\
Hipoclorito de sodio al 2\% & 15 & 0.00 & 0.00 & 0.001 \\
Total & 30 & & & \\
\hline
\end{tabular}

a: Basado en la prueba no paramétrica U de Mann-Whitney; n: muestra; UFC: unidades formadoras de colonias; DE: desviación estándar; p<0.05: estadísticamente significativo.

De la tabla 3 se observa que existe diferencia estadísticamente significativa entre el efecto antibacteriano del peróxido de hidrógeno al $6 \%$ y el hipoclorito de sodio al $2 \%(p=0.001)$.

Tabla 4. Comparación del efecto antibacteriano del peróxido de hidrógeno al $6 \%$ con el hipoclorito de sodio al $2 \%\left(\times 10^{9} \pm \mathrm{DE}\right)$

\begin{tabular}{lcccc}
\hline \multicolumn{1}{c}{ Grupo } & n & $\begin{array}{c}\text { Media } \\
\text { (Ufc/mL) }\end{array}$ & $\begin{array}{c}\text { DE } \\
\text { (UFc/mL) }\end{array}$ & Valor de $\boldsymbol{p}^{\mathbf{a}}$ \\
\hline Hipoclorito de sodio al 1\% & 15 & 0.40 & 0.63 & \\
Hipoclorito de sodio al 2\% & 15 & 0.00 & 0.00 & 0.02 \\
Total & 30 & & & \\
\hline
\end{tabular}

a: basado en la prueba no paramétrica U de Mann-Whitney; n: muestra; UFC: unidades formadoras de colonias; DE: desviación estándar; p<0.05: estadísticamente significativo.

De la tabla 4 se observa que existe diferencia estadísticamente significativa entre el efecto antibacteriano del hipoclorito de sodio al $1 \%$ y al $2 \%(p=0.02)$. 


\section{Discusión}

T a presente investigación se limitó a evaluar el efecto antibacteriano del perióxido de Lhidrógeno al $6 \%$ y el hipoclorito de sodio al 1\% y al $2 \%$ sobre cepillos dentales inoculados con Streptococcus mutans Aтсс $^{\circledR} 25175^{\mathrm{TM}}$. Como dificultad se tuvo que el trabajo de activación y sembrado para todos los grupos del experimento requería un periodo de 24 a $48 \mathrm{~h}$, y una vez realizado, cada $48 \mathrm{~h}$ se debía cambiar el agar de cultivo para mantener las cepas activas.

Assed et al. demostraron que el Streptococcus mutans permanece viable en las cerdas de los cepillos dentales durante $44 \mathrm{~h}$ (9); por ello, en esta investigación se tomó la muestra dentro de este tiempo, después de la inoculación de cepillos con Streptococcus mutans, y así se obtuvo, a las 24 horas de haberse sumergido el cepillo en el agua destilada, el valor de $250 \times 10^{9} \mathrm{ufc} / \mathrm{mL}$.

Basman et al. determinaron que el hipoclorito de sodio al $2 \%$ no elimina todos los Streptococcus mutans de los cepillos dentales, lo cual difiere de los resultados obtenidos en esta investigación, puesto que se demostró que dicha solución elimina totalmente al Streptococcus mutans del cepillo dental (10). A pesar de que se usó el mismo tiempo de exposición, es probable que la diferencia se deba a que las soluciones empleadas en estos dos estudios fueron de diferente procedencia de marca comercial y país, lo que podría influir en el control de calidad del producto, respecto a la concentración.

En el estudio realizado por Peker et al., los autores demostraron que el hipoclorito de sodio al $1 \%$ no es totalmente eficaz para la desinfección de cepillos dentales (12); sin embargo, sus efectos disminuyeron considerablemente las unidades formadoras de colonias de Streptococcus mutans. Estos resultados son similares con lo obtenido en esta investigación, probablemente porque se empleó el mismo tiempo de aplicación (10 min). De ahí que se recomiende evaluar la solución de hipoclorito de sodio al $1 \%$ a mayor tiempo, hasta demostrar en cuánto tiempo de exposición la eficacia se hace constante.

Por otro lado, Salazar-Chicaiza y Zurita-Solis determinaron que el peróxido de hidrógeno al $6 \%$ no es totalmente efectivo y no elimina todo microrganismo del cepillo dental (2). Ello es similar a lo obtenido en la presente investigación, lo que corroboraría su incompleta eficacia frente al Streptococcus mutans, puesto que se aplicó similar metodología.

Según Do Nascimento et al., los enjuagues bucales que contienen gluconato de clorhexidina al $0.12 \%$ son más efectivos en la reducción de bacterias de los cepillos dentales (7); mientras que en esta investigación se demostró que el hipoclorito de sodio al $2 \%$ es totalmente efectivo en la eliminación del Streptococcus mutans, aun cuando se resalta que en este estudio no se hizo comparación con el gluconato de clorhexidina al $0.12 \%$. Por ello, se recomienda que futuras investigaciones validen este aspecto. 
En el 2016, Han y Dong evaluaron la actividad antibacteriana del hipoclorito de sodio al $6 \%$ frente al Streptococcus mutans y demostraron que fue totalmente eficaz como antibacteriano después de 30 min de aplicación; mientras que en la presente investigación se obtuvo el mismo resultado, pero con hipoclorito de sodio al $2 \%$ y a 10 min de la aplicación. Ello sugeriría la concentración y el tiempo mínimo de aplicación requerido de la solución de hipoclorito de sodio al $2 \%$ para lograr completa efectividad antimicrobiana frente al Streptococcus mutans (19).

La importancia de la presente investigación radica en que al demostrarse la efectividad total de la solución del hipoclorito de sodio al $2 \%$ frente al Streptococcus mutans presente en los cepillos dentales, nos permite brindar una alternativa segura de desinfección del cepillo, al sumergir la parte activa durante 10 min en dicha solución desinfectante, antes de proceder a higienizarse la cavidad oral y, de esta manera, se evitará aumentar la cantidad de carga bacteriana bucal del principal agente de la caries, así como disminuir la posibilidad de infección cruzada por almacenamiento compartido del cepillo.

Se recomienda llevar a cabo más estudios y comparar la eficacia antibacteriana, frente al Streptococcus mutans de la solución de hipoclorito de sodio al $2 \%$ versus otros desinfectantes, como la clorhexidina al $2 \%$ y el vinagre blanco al $50 \%$ y al $100 \%$, a diferentes tiempos de inmersión total de la parte activa del cepillo dental, ya que estas últimas soluciones han demostrado en otras investigaciones tener buen efecto antibacteriano frente a otros microrganismos de la cavidad oral (10).

Se concluye en esta investigación que la solución del hipoclorito de sodio al $2 \%$ es totalmente efectivo frente al Streptococcus mutans; mientras que el peróxido de hidrógeno al $6 \%$ y el hipoclorito de sodio al $1 \%$ presentan efectos antibacterianos similares y no totalmente efectivos frente al Streptococcus mutans.

\section{Contribución de los autores}

Todos los autores contribuyeron en la concepción y elaboración del manuscrito, además 1 de la redacción, revisión crítica y aprobación de su versión final.

\section{Conflicto de intereses}

Ninguno declarado. 


\section{Referencias}

1. Villacis Sánchez JL. Identificacion de Enterococcus faecalis en cepillos dentales y evaluación in vitro de su grado de susceptibilidad frente a hipoclorito de sodio y gluconato de clorhexidina [tesis de grado en internet]. Quito: Universidad de las Américas; 2016. Disponible en: http://dspace.udla.edu.ec/handle/33000/5528

2. Salazar-Chicaiza SA, Zurita-Solis MK. Presencia de microorganismos en cepillos dentales y su desinfección con H2O2. Dom Cien [internet]. 2016;2(1):155-67. Disponible en: https:// docplayer.es/27162535-Presencia-de-microorganismos-en-cepillos-dentales-y-su-desinfeccion-con-h2o2-presence-of-microorganisms-on-toothbrushes-and-disinfection-withh-2-o-2.html

3. Abranches J, Zeng L, Kajfasz JK, Palmer SR, Chakraborty B, Wen ZT, et al. Biology of oral Streptococci. Microbiol Spectr. 2018;6(5):1-18. https://doi.org/10.1128/microbiolspec. GPP3-0042-2018

4. Gevers D, Knight R, Petrosino JF, Huang K, McGuire AL, Birren BW, et al. The Human Microbiome Project: a community resource for the healthy human microbiome. PLoS Biol. 2012;10(8):e1001377. https://doi.org/10.1371/journal.pbio.1001377

5. Huse SM, Ye Y, Zhou Y, Fodor AA. A core human microbiome as viewed through $16 \mathrm{~S}$ rRNA sequence clusters. PLoS One. 2012;7(6):e34242. https://doi.org/10.1371/journal. pone.0034242

6. Nascimento MM, Zaura E, Mira A, Takahashi N, Ten Cate JM. Second era of omics in caries research: moving past the phase of disillusionment. J Dent Res. 2017;96(7):733-40. https://doi.org/10.1177 / 0022034517701902

7. Do Nascimento C, Balero M, Murillo SP, Carriço FH, Linares P, Watanabeet E, et al. Effectiveness of three antimicrobial mouthrinses on the disinfection of toothbrushes stored in closed containers: a randomized clinical investigation by DNA checkerboard and culture. Gerondontology. 2014;31(3):227-36. https://doi.org/10.1111/ger.12035

8. Frazelle MR, Munro CL. Toothbrush contamination: a review of the literature. Nurs Res Pract. 2012;2012: 420630. https://doi.org/10.1155/2012/420630

9. Assed Bezerra Da Silva L, Nelson-Filho P, Saravia ME, De Rossi A, Lucisano MP, Assed Bezerra Da Silva R. Mutans streptococci remained viable on toothbrush bristles, in vivo, for 44 h. Int J Paediatr Dent. 2014;24(5):367-72. https://doi.org/10.1111/ipd.12079

10. Basman A, Peker I, Akca G, Alkurt MT, Sarikir C, Celik I. Evaluation of toothbrush disinfection via different methods. Braz Oral Res. 2016;30:S1806-83242016000100203. https:// doi.org/10.1590/1807-3107BOR-2016.vol30.0006

11. Akca E, Akca G, Toksoy F, Macit N, Pikdöken L, Özgen Y. The comparative evaluation of the antimicrobial effect of propolis with chlorhexidine against oral pathogens: an in vitro study. Biomed Res Int. 2016;2016:3627463. https://doi.org/10.1155/2016/3627463

12. Peker I, Akca G, Sarikir C, Toraman M, Celik I. Effectiveness of alternative methods for toothbrush disinfection: an in vitro study. ScientificWorldJournal. 2014;2014:726190. https://doi.org/10.1155/2014/726190 
13. Salvia AC, Matilde FS, Rosa FC, Kimpara ET, Jorge AO, Balducci I, et al. Disinfection protocols to prevent cross contamination between dental offices and prosthetic laboratories. J Infect Public Health. 2013;6(5):377-82. https://doi.org/10.1016/j.jiph.2013.04.011

14. Sánchez Ruiz FH, Furuya Meguro AT, Arroniz Padilla S, Gómez Moreno A, Gómez L. Comparación de la acción bactericida del hipoclorito de sodio y Microcyn 60. Rev Odont Mex. 2009. 13(1):9-16. https://doi.org/10.22201/fo.1870199xp.2009.13.1.15613

15. Muratovska I, Kitagawa H, Hirose N, Kitagawa R, Imazato S. Antibacterial activity and dentin bonding ability of combined use of Clearfil SE Protect and sodium hypochlorite. Dent Mater J. 2018;37(3):460-64. https://doi.org/10.4012/dmj.2017-294

16. Lamont RJ, Hajisshengallis GN, Jenkinson HF. Microbiología e inmunología oral. México: Manual Moderno; 2015.

17. Ahn KB, Kim AR, Kee-Yeon K, Cheol-Heui Y, Seung H. The synthetic human beta-defensin-3 C15 peptide exhibits antimicrobial activity against Streptococcus mutans, both alone and in combination with dental disinfectants. J Microbiol. 2017;55(10):830-36. https://doi.org/10.1007/s12275-017-7362-y

18. Dadpe MV, Dhore SV, Dahake PT, Kale YJ, Kendre SB, Siddiqui AG. Evaluation of antimicrobial efficacy of Trachyspermum ammi (Ajwain) oil and chlorhexidine against oral bacteria: an in vitro study. J Indian Soc Pedod Prev Dent. 2018;36(4):357-63. https://doi. org/10.4103/JISPPD.JISPPD_65_18

19. Han-Sol C, Dong-Hoon S. Antibacterial capacity of cavity disinfectants against Streptococcus mutans and their effects on shear bond strength of a self-etch adhesive. Dent Mater J. 2016;35(1):147-52. https://doi.org/10.4012/dmj.2015-175

20. Hernández Sampieri R, Fernández Collado C, Baptista Lucio P. Metodología de la investigación. 6. ${ }^{\text {a }}$ ed. México: McGraw-Hill; 2014. 